\title{
Examining inclusive mobility through smartcard data: What shall we make of senior citizens' declining bus patronage in the West Midlands?
}

\author{
Jens Kandt, ${ }^{*}$ Alistair Leak \\ The Bartlett Centre for Advanced Spatial Analysis, University College London. \\ *Corresponding author: j.kandt@ucl.ac.uk
}

\section{Acknowledgements}

The work for this article was funded by the ESRC funding scheme 'Big Data Phase 3: New and Emerging Forms of Data' (reference ES/P010741/1). We wish to thank the coinvestigators Paul Longley, UCL and the ESRC Consumer Data Research Centre (CDRC), and Chris Lane, Transport for West Midlands (TfWM), as well as the TfWM team, notably Daniel Pass, Phillip Evans, Robert Walker and Anna Schweickert for all the support and exchange, which made this paper possible. Furthermore, we are grateful to Sarah Sheppard (CDRC) for managing and facilitating secure data access at CDRC.

\begin{abstract}
Free access to public transport is viewed as an effective means to enable inclusive mobility, but the recent decline in bus patronage by passengers entitled to free travel in the West Midlands and other UK regions presents a conundrum to transport research and policy. In this research, we analyse travel smartcard transactions recorded over nearly six years for 371,220 concessionary passengers resident in the West Midlands Combined Authority. Using sequence analysis, we identify six groups representing different temporal boarding profiles. We link these profiles to geo-spatial data and characterise them by means of spatial pattern detection and multinomial logit modelling. We find that, first, the decline in patronage occurs in three waves across the study period according to distinct activity patterns; second, formerly frequent (daily) passengers tend to abandon the bus and thus show the largest impact on the overall trend; third, the neighbourhood context of withdrawing passengers indicates social disadvantage, higher instance of ethnic minorities and lower car ownership rates, in other words higher risk of social exclusion. To discuss these in parts paradoxical results, we identify three causal domains - social, health-related and structural - and conclude with implications for policy promoting inclusive and healthy mobility in later life.
\end{abstract}

\section{Keywords}

mobility \& ageing; public transport; sequence analysis; smartcard data; spatial analysis 


\section{Highlights}

- We link nearly six years of smartcard data to study issues of inclusive mobility.

- We unpack the conundrum of declining free bus travel among senior citizens.

- We find that the declining patronage is associated with social disadvantage.

- We develop an evidence matrix of potential causes for policy consideration.

\section{Background}

\section{Mobility in an ageing society}

Delivering inclusive and sustainable transport is an important policy goal for transport authorities in the United Kingdom and in other countries. Public transport is expected to play a major part in this endeavour, particularly in view of the continuing demographic transition towards older age groups. In the United Kingdom, nearly one in four residents will be 65 years or above by 2040 due to the compound effect of declining fertility rates and increased longevity, moderated in parts by immigration (ONS 2017). Together with continuous technological developments, this shift is expected to place new kinds of demand on the transport system and to alter visions of inclusive and healthy mobility (Luiu et al 2017).

Mobility, a person's ability to move freely in pursuit of activities, has come to be a prerequisite for autonomy and independence in later life and hence crucial for successfully ageing societies (Musselwhite et al 2015; Ziegler \& Schwanen 2011; Schwanen et al 2012). The widespread expansion of mobility co-evolves with new notions of ageing, both of which define expectations towards transport systems. Musselwhite et al (2015) argue that in today's 'hypermobile world', mobility increasingly determines health and well-being in later life. Such arguments chime with the mobilities paradigm (Sheller \& Urry 2006), which identifies mobility as the defining source of social experience in contemporary, globalised society (Urry 2014).

Researchers have repeatedly observed distinctive tendencies in the mobility practices of older populations. Senior residents travel shorter distances, visit fewer destinations in total, with grocery stores, other retailers and gastronomy being the main ones, and make fewer trips by individualised modes, including cars and bicycles (Chyduk et al 2015; Mackett 2017; Schwanen \& Paez 2010). Different travel patterns by the elderly population can regularly be attributed to a higher incidence of mobility-limiting conditions, although technological developments can attenuate the experience of immobility.

Yet empirical evidence also suggests that these patterns are changing. Van Den Berg et al. (2011) found in the Netherlands that today's older populations are as mobile as younger ones with respect to non-work trips. Average travel distance did not decrease with age; instead they were often affected by other factors, such as education, residential location, gender and household structure. Siren and Haustein found significant heterogeneity not only among elderly residents (Haustein 2012) but also between different cohorts (Siren \& Haustein 2013, 2016). Over and above biological age, mobility practices reflect individual 
lifestyle practices, leisure activities, engagement in social networks, and structural constraints related to residential location. As older population cohorts become more socially and culturally diverse, maintain professional engagements and access new leisure opportunities, the ways senior residents will travel in the future remain uncertain (Siren \& Haustein 2016).

In summary, inclusive mobility can be understood as a relational outcome of subjectively experienced mobility needs, social expectations towards mobility, access to transport, the institutional practices and perceived opportunities to influence strategic decisions on transport (Lucas 2012; Schwanen et al 2015). As a consequence, the broad force of the demographic transition does not automatically prescribe a fixed notion of an 'age-friendly' transport system, and there is a constant need to study evolving mobility needs and practices and how they are realised or not through available means (Cui et al 2017; Luiu et al 2017).

\section{Understanding trends in public transport patronage}

Recognising the importance of mobility for independent and autonomous living, the UK Department for Transport has introduced the English National Concessionary Travel Scheme (ENCTS), which entitles residents of pensionable age to free bus travel after 9.30 am on weekdays and at all times on weekends. The concessionary scheme is available to younger people with disabilities, too. Local transport authorities administer the scheme, where it is often the largest standing item in local transport revenue budgets (TfWM 2018). In 2010 , residents were eligible at age 60 , and since then, the eligibility age increased by six months annually.

A recent review of ENCTS found that the one-billion pounds programme generates diverse benefits amounting to $£ 2.87$ per pound invested (Greener Journeys \& KPMG 2014). In terms of health and well-being, access to free public transport can reduce social exclusion in older age, contribute to life satisfaction and protect physical health (Green et al 2014; Mackett 2013; 2014; Webb et al 2016). Although the actual benefits often remain intangible, research on the scheme's uptake highlights that ENCTS enjoys high levels of popularity among older residents (Mackett 2014).

Yet, these favourable accounts on ENCTS contrast with the experience of transport authorities, such as Transport for West Midlands (TfWM), the transport provider for the West Midlands Combined Authority. TfWM has recorded a sharp decline in bus patronage by ENCTS passengers. Bus ticket sales and issuance data indicate a drop by 29 per cent since 2009 (WMOD 2018). Such a trend raises obvious concerns in the discourse on inclusive mobility.

Travel smartcard transactions recorded by Automated Fare Collection systems may provide additional evidence on trends in mobility practices by the older population. There is now extensive experience in mining and processing smartcard data for a variety of research and transport planning purposes (Anda et al 2017; Pelletier et al 2011; Yue et al 2014). Some of the most powerful features of smartcard data are the temporal precision and the operational 
detail that is captured for each journey. Smartcard transactions, most often representing boardings of vehicles, can be linked longitudinally, thus making possible the creation of individual boarding sequences at different time scales. The longitudinal structure combined with temporal precision presents an important advantage of such data sources over conventional surveys (Spurr et al 2015; Yue et al 2014). Yet, this advantage is accompanied by widely acknowledged drawbacks, such as bias, privacy concerns, reliance on assumptions and computational cost.

In view of these challenges, boarding sequences derived from smartcard data have rarely been prepared for longer time periods. Most research application are limited to short time periods, such as a day or multiple weeks (e.g. Goulet Langlois et al 2016; Joh \& Timmermans 2011; Tao et al 2014), and there are only a few exceptions, such as the study by Huang et al (2018), who link a small sample ( 4,000 passengers) of smartcard data over seven years, Chu (2015), who link smartcard records over a period of two years, or Briand et al (2017), who analyse linked transactions in five months across five years. These studies notwithstanding, understanding and addressing complex challenges, such as inclusive and healthy mobility, require a significant body of long-term evidence on evolving mobility practices of a wide range of passengers.

\section{Research objective and design}

In this research, we mine travel smartcard transaction by 371,220 ENCTS passholders who are of age 66 or older and reside in the West Midlands Combined Authority. The objective is to unpack and contextualise the sharp drop in public transport patronage observed between 2010 and 2016. Linking approximately 300 million journeys made over nearly six years, we create boarding sequences and segment concessionary passengers into six groups representing distinct temporal boarding patterns. Subsequent spatial and statistical analysis of these boarding trends reveal the social and neighbourhood contexts in which differential boarding trends occur. Based on the contextual characterisation, we identify and discuss three causal domains that may explain these trends.

\section{Data}

Between 2009 and 2010, TfWM rolled out the SWIFT travel smartcard to all concessionary passengers in the West Midlands Combined Authority. Since then, passengers are required to use their cards to validate their free bus and tram travel. By the end of 2010, the vast majority of ENCTS pass holders possessed a smartcard for travel. Therefore, most journeys are recorded on these cards except for journeys that commenced before 9.30am, which are not covered by the concessionary scheme and may therefore have been made using conventional paper tickets.

The smartcards record numerous boarding details, including the card ID, the timestamp of the boarding, technical details related to the ticketing machine, the route and operator. We use the card ID to link the transactions to a database of anonymised cardholder accounts to identify all transactions pertaining to the same user. Several cards can be registered for one 
user, if cards have been reissued. Therefore, the account ID is used to generate boarding sequences for passengers. The cardholder database also stores gender, age and residential area as Lower Super Output Area (LSOA) used by the UK Census (ONS 2018a). The data can be accessed through the ESRC Consumer Data Research Centre (www.cdrc.ac.uk) on application, scientific review and ethical scrutiny. We processed the data in the centre's secure data lab, which meets ISO 27001 information security standards.

We use the LSOAs to link in administrative datasets, which comprise Census neighbourhood statistics (ONS 2018a) and the Index of Multiple Deprivation (IMD) (MHCLG 2015). From these data, we derive variables describing residential context, including ethnic structure, car ownership rates, socio-economic structure as IMD dimension on income in old age and the IMD health dimension.

We also develop indicators of neighbourhood accessibility to local destinations, including clinics, GP practices, hospitals, railway stations, retail catchments and supermarkets. The loactions of these amenities are available in datasets provided by NHS Digital (NHS Digital 2018), Geolytix (2018) and the ESRC Consumer Data Research Centre (data.cdrc.ac.uk; Pavlis et al 2017). Using the Integrated Transport Network (ITN) prepared by Ordinance Survey (Ordinance Survey 2018) in conjunction with timetables provided by TfWM, we calculate dynamic accessibility similar to the studies by Farber et al (2014) and Tenkanen et al (2016). Specifically, we run the OpenTripPlanner API (OpenTripPlanner 2018) to query walk and bus travel times from each population-weighted Output Area centroids (ONS $2017 \mathrm{~b}$ ) to the five closest instances of each local amenity. We repeat this for every 10 minutes between 10 and 11 am on a Tuesday in October for each year and calculate, first, the average for each Output Area, and second, the average for each LSOA weighted by the Output Area population counts of residents of age 65 or older. The result is a weighted accessibility index for each LSOA neighbourhood and amenity reflecting travel times and level of service. We also estimate walking distance to tram stops based on the ITN.

\section{Statistical methods}

Our research design consists of two major stages: (1) passenger segmentation and (2) interpretation/contextualisation based on profiling of boarding patterns of each segment, spatial pattern detection and multinomial logit modelling (Figure 1). The findings from this process are summarised in a set of hypotheses on what may cause distinct boarding trends, which we triangulate against external evidence.

In the first stage, we transform the passenger-linked transactions into ordinal boarding sequences and count the number of boardings in 76 four-week episodes between 1 October 2010 and 18 July 2016. The raw counts of boardings are grouped into quintiles representing the categories of no boarding, one to four, five to 11,12 to 26 and 27 or more boardings. The latter category typically corresponds to daily bus use. 


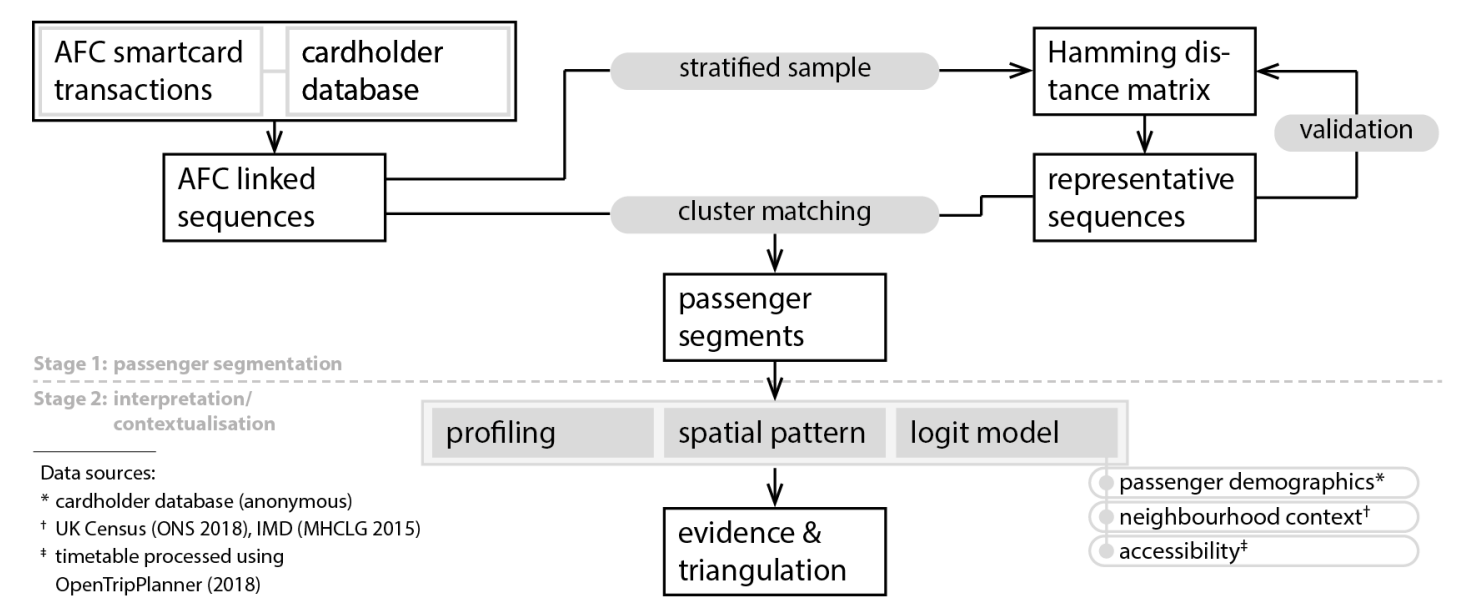

Figure 1. The research process of this study.

Due to changes in the eligibility to ENCTS, we excluded passengers of age 65 or less in 2016, because they were not eligible throughout the entire period. We will discuss the impact of this exclusion below. We also exclude passengers with missing data on age, sex or LSOA. Applying these criteria, we generate 371,220 five-point ordinal boarding sequences corresponding to all registered passengers of age 66 or more with complete data.

Following the procedure described by Gauthier et al (2014), we use these sequences to identify groups of similar temporal activity profiles. Segmentation based on boarding sequences involves a pair-wise comparison of each individual sequence. The pair-wise comparison incurs superlinear computational cost and hence remains unfeasible for large samples. Joh \& Timmermans (2011) have developed heuristics that allow multidimensional sequence analysis for large sample over short time horizon. Applying a similar logic adapted to long time horizons, we take a 14.5 per cent random sample of the 371,220 sequences $(n=53,647)$. We stratify the sampling by four age bands $(66-70,71-75,76-80,81$ or more), gender and residential area (LSOA) to ensure an even distribution among all available demographic categories and full geographical coverage. We segment the sample and identify representative sequences for each segment, which we then use to assign the remaining $317,573(=371,220-53,647)$ to the best matching segments.

We use the Hamming algorithm (Hamming 1950) to determine distances between sequences based on their episodes and the difference of points in the ordinal categories. The Hamming distance between two sequences is the number of episodes that need to change states, weighted by the difference in ordinal points, to make the two sequences identical. This algorithm is simpler than the more commonly used Optimal Matching (Levenshtein 1966), which allows insertions and deletions and thus processes the information held in adjacent episodes and thus better identifies seasonal patterns. But this algorithm is computationally intensive and consequently only permits very small seed 
samples. In addition, since our focus is on longer temporal trends and not seasonal patterns, we deem the Hamming algorithm appropriate for our research.

The Hamming algorithm produces a distance matrix between pairs of sequences.

Hierarchical clustering algorithms are ideal to process distance matrices to detect clusters, in our case structurally similar segments of boarding trends. We apply Ward's algorithm (Everitt et al 2011) and decide the optimal number of clusters based on a range of internal cluster quality criteria. On most criteria, a six or seven-cluster solution emerges as the best performing, and after reviewing both, we chose the more parsimonious and equally sized cluster solution with six clusters. We then generate for each cluster the most representative (i.e. frequent) sequences and use these to predict the cluster membership of our 53,647 seed sequences. We develop a confusion matrix to identify convergent and divergent cluster predictions between the initial clustering and the one based on representative sequences. We then calculate the kappa coefficient $\mathcal{X}$ (Cohen 1968), which measures the level of agreement based on convergent and divergent predictions and adjusted for chance. A $\varkappa$ of 1 indicates complete agreement and, in our case, suggests that clustering on the number of representative sequences is optimally accurate for the sample. A value of 0 indicates that the agreement is no higher than expected by chance. We iteratively increase the number of representative sequences until $\mathcal{H}$ reaches a level of .95 . We then use this final set of representative sequences to predict cluster membership of the remaining 317,573 sequences.

Having determined the sequence cluster for all cardholders, we link the cluster membership of each sequence to the cardholder account and use the LSOA reference to explore the geographic concentration of each cluster. We identify geographic concentrations by means of Local Indicators of Spatial Autorcorrelation (LISA) (Anselin 1995). LISA measures spatial autocorrelation and identifies spatial concentrations or sparseness of phenomena, in our case passengers who belong to a particular sequence cluster. We visually inspect the resulting geographical pattern and discuss them with local experts at TfWM to derive potential contextual factors the segments may be associated with.

The geographic pattern detection informs the last step, the building of a predictive model. We specify a multinomial logit model estimating cluster membership based on individual age and gender and the above-mentioned neighbourhood social and accessibility indicators. This model presents a formal analysis of passenger and contextual factors that may be associated with different temporal boarding profiles. Due to computational limitations, we apply this analysis only to the sample of 53,647 passholders. We fit random intercepts for each LSOA to account for the hierarchical (multilevel) structure of individuals nested in neighbourhoods. Conforming to a Bayesian framework, we use vague priors as recommended by Hadfield (2010). We use the R package MCMCglmm developed by the same author, which estimates parameters of posterior distributions using MCMC chains. We run 200,000 iterations with a burnin period of 100,000 to ensure a high level of convergence. Apart from that, we use the base package of the software $R$ ( $R$ Core Team 2017) for analysis, the package TraMineR (Gabadinho et al 2011; Studer \& Ritschard 2016) for 
sequence analysis, flashClust (Langfelder \& Horvarth 2012) for cluster analysis, WeightedCluster (Studer 2013) for cluster evaluation, spdep (Bivand \& Piras 2015) for spatial pattern detection.

\section{Results}

We first compare the demographic composition of smartcard passholders against that of the regional population. The objective is to assess potential bias and thus add context to interpreting the sequence clusters. In so doing, we consider general demographic trends in the region and regulatory changes with respect to ENCTS eligibility.

\section{General trends in patronage and eligibility}

The full ENCTS passenger population captured in the smartcard data comprise 431,457 account holders, of whom 396,413 are 66 or older. In both the general population as well as among passholders, there are more women than men. In both populations, the share of women rises in older age groups, due to the typical gender pattern associated with life expectancy. The figures suggest that a high share of ENCTS-eligible passengers is captured in the smartcard data, although it may still hold passengers that have moved or deceased. In particular, the database holds more than 48,000 male passengers of age 81 or older, although there are only 37,000 according to official population estimates.

Table 1. Passholder, sample and regional population statistics

\begin{tabular}{llrrrrr} 
age band & sex & \multicolumn{2}{c}{ population* } & TfWM passholders & 14.5\% sample \\
\hline $61-65$ & female & 68,464 & $(50.7 \%)$ & $19,401(55.4 \%)$ & - & - \\
& male & 66,690 & $(49.3 \%)$ & $15,643(44.6 \%)$ & - & - \\
\hline $66-70$ & female & 58,882 & $(52.1 \%)$ & $58,640(52.2 \%)$ & $7,924(52.2 \%)$ \\
& male & 54,233 & $(47.9 \%)$ & $53,695(47.8 \%)$ & $7,267(47.8 \%)$ \\
\hline $71-75$ & female & 52,277 & $(53.5 \%)$ & $48,544(52.6 \%)$ & $6,588(52.6 \%)$ \\
& male & 45,465 & $(46.5 \%)$ & $43,825(47.4 \%)$ & $5,933(47.4 \%)$ \\
\hline $76-80$ & female & 43,976 & $(55.9 \%)$ & $41,651(53.7 \%)$ & $5,631(53.8 \%)$ \\
& male & 34,716 & $(44.1 \%)$ & $35,844(46.3 \%)$ & $4,830(46.2 \%)$ \\
\hline 81 plus & female & 65,712 & $(64.0 \%)$ & $65,330(57.2 \%)$ & $8,852(57.2 \%)$ \\
& male & 37,041 & $(36.0 \%)$ & $48,884(42.8 \%)$ & $6,622(42.8 \%)$ \\
\hline \multirow{2}{*}{ total } & female & 289,311 & $(54.9 \%)$ & $233,566(54.1 \%)$ & $28,995 \quad(54.1 \%)$ \\
& male & 238,145 & $(45.2 \%)$ & $197,891 \quad(45.9 \%)$ & $24,652 \quad(46.0 \%)$ \\
\hline
\end{tabular}

* authors' calculations based on ONS (2019).

Up to 2010 , all passengers of age 60 or more were eligible to the concessionary scheme. Since then, the eligibility age has been gradually increased in line with the female state pension age. As a result, the eligible population in the WMCA has reduced by 10 per cent (Table 2). Annual boardings estimated from smartcard transaction have dropped by more than 25 per cent during the same time period. Viewing only passengers that were eligible throughout the entire time period, i.e. those that were 66 years or older in 2016, we perceive a similar 10-percent-gap between the number of residents in that age group and the number 
of boardings. But during the earlier years, boarding counts remained stable, which indicates that there has been a relative increase in boarding rates with a sharp drop after 2014.

Table 2. Expected and actual boardings of (a) eligible residents and (b) the population cohorts of age 66 or more in 2016.

\begin{tabular}{|c|c|c|c|c|c|c|c|}
\hline & 2010 & 2011 & 2012 & 2013 & 2014 & 2015 & 2016 \\
\hline \multicolumn{8}{|l|}{ (a) eligible population } \\
\hline eligibility age & 60.0 & 60.5 & 61.0 & 61.5 & 62.0 & 62.5 & 63 \\
\hline eligible residents & 551,000 & 542,486 & 533,576 & 524,137 & 515,689 & 506,028 & 496,795 \\
\hline residents (indexed 2011) & 101.6 & 100.0 & 98.4 & 96.6 & 95.1 & 93.3 & 91.6 \\
\hline boardings (indexed 2011)* & 89.9 & 100.0 & 99.4 & 98.2 & 100.1 & 90.1 & 74.5 \\
\hline \multicolumn{8}{|c|}{ (b) resident cohort of age 66 or more in 2016} \\
\hline minimum age in cohort & 60 & 61 & 62 & 63 & 64 & 65 & 66 \\
\hline residents & 551,000 & 529,189 & 507,257 & 485,013 & 464,096 & 441,798 & 420,303 \\
\hline residents (indexed 2011) & 104.2 & 100.0 & 95.9 & 91.7 & 87.7 & 83.4 & 79.5 \\
\hline boardings (indexed 2011)* & 91.1 & 100.0 & 97.2 & 93.8 & 93.3 & 83.3 & 69.6 \\
\hline
\end{tabular}

The descriptive comparison suggests that there is an overall decline in patronage, but there may be significant heterogeneity at a finer grouping of eligible residents. Furthermore, the decline cannot be attributed to demographic events (death, migration) alone because it exceeds the level expected based on demographic changes in the region. A segmentation of passenger boarding sequences may therefore uncover heterogeneity and help further contextualise and interpret trends in concessionary public transport patronage.

\section{Temporal profiles of boarding sequences}

In order to remove the effect of changing eligibility, we only include passengers who were eligible throughout the entire study period in the analysis of boarding sequences. We identify six groups of self-similar temporal boarding profiles from the clustering of boarding sequences (Figure 2). The first cluster comprises rarely seen passengers. It is the largest cluster with 55 per cent of all passengers. About one in four of these passengers has never used the bus throughout the entire study period, while another one in four used the bus throughout the period, but rarely made more than four boardings in a four-week episode. Another one in four began using the bus between spring 2011 and end of 2012, and the last one in four used the system since then.

A second cluster is formed by irregular passengers, who use the system throughout the study period more frequently than the rarely seen passengers of cluster 1 . A proportion of 14 per cent of all passholders belong to this group. In any four-week episode, 60 per cent of passengers board the bus up to four times, but the incidence of passengers making no boarding at all doubled in 2016.

The third cluster describes patterns that pertain to regularly seen passengers. For most of the study period, about half of the passengers make between one and two dozen boardings per four-week episode. On average, this translates into at least two to three trips per week. 
1 - Rarely seen passengers $(n=217,203,55 \%)$

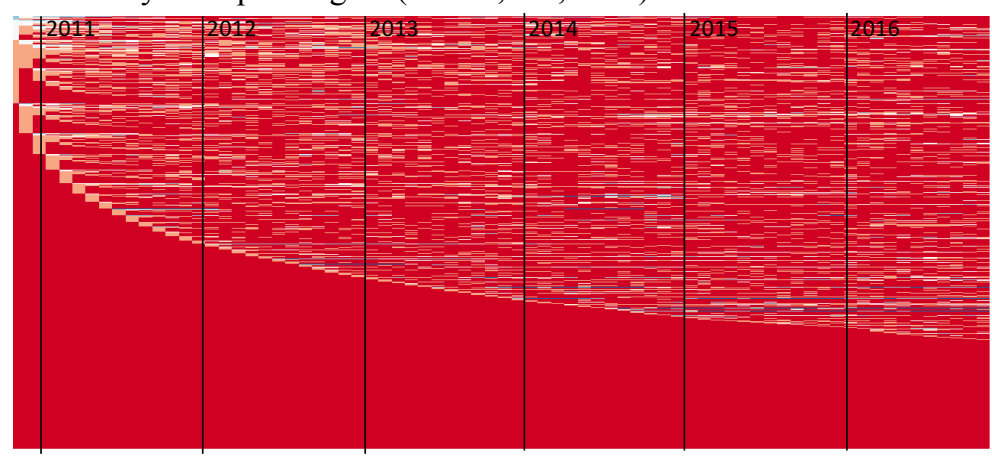

2 - Irregular passengers $(n=55,990,14 \%)$

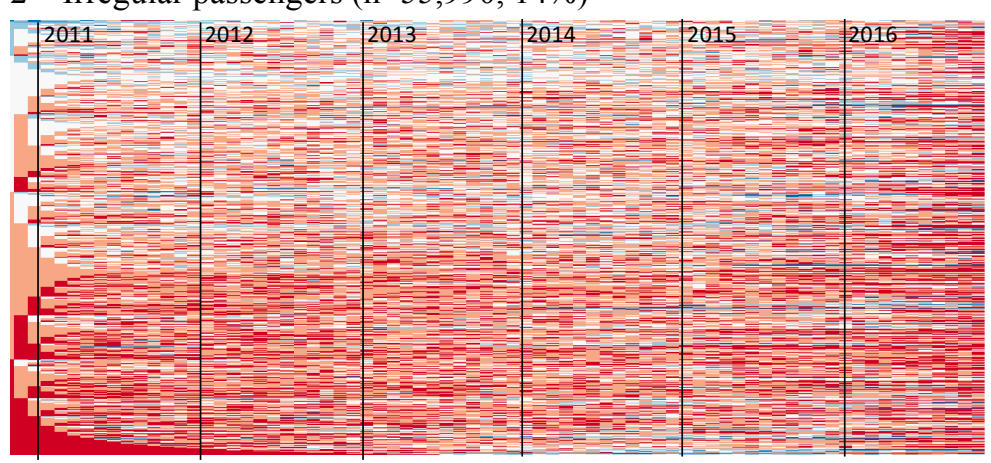

3 - Regularly seen passengers $(n=31,911,8 \%)$

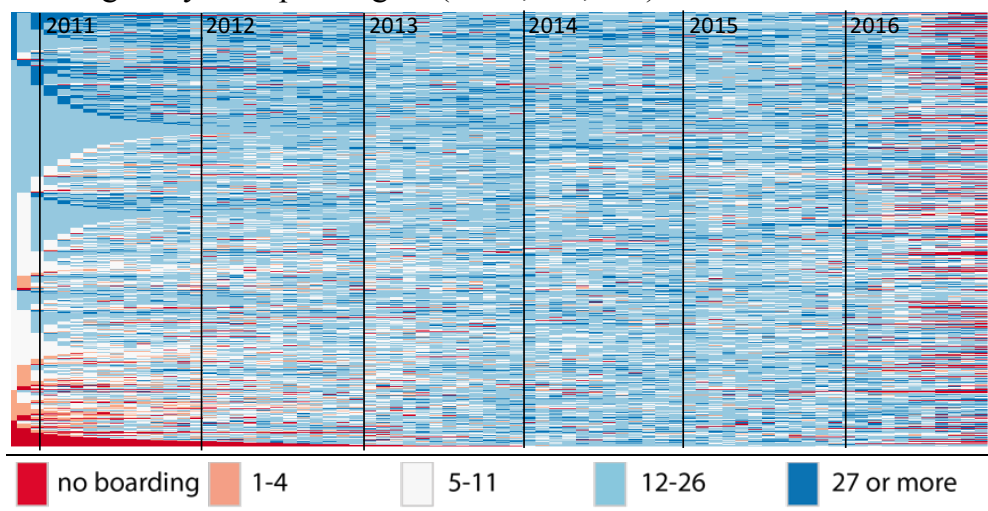

4 - Gradually withdrawing passengers $(n=27,077,7 \%)$

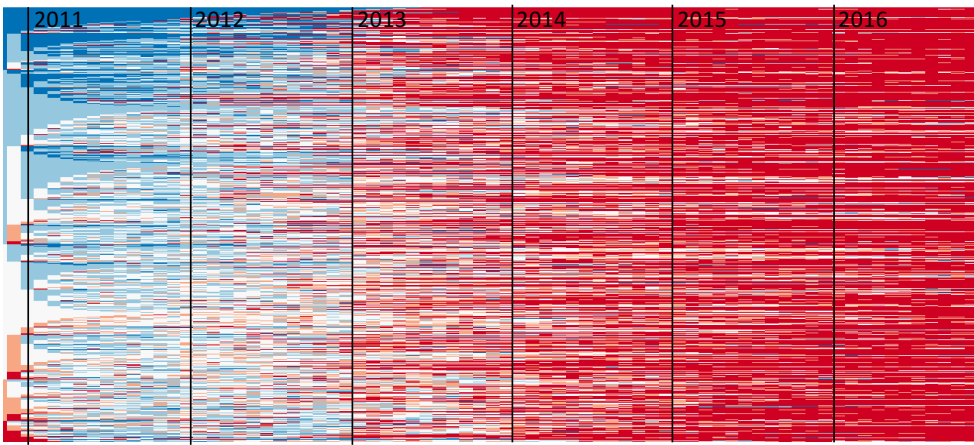

5 - Rapidly withdrawing passengers post $2015(\mathrm{n}=18,620,5 \%)$

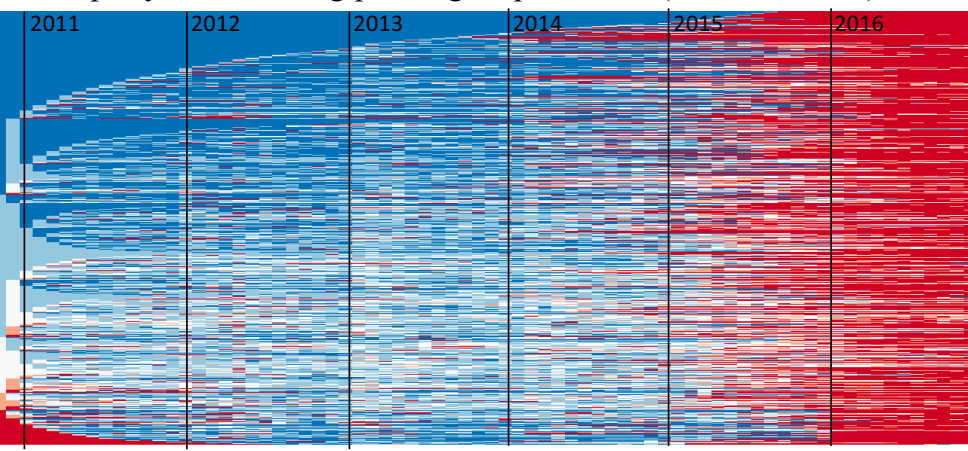

6 - Daily passengers $(n=45,623,12 \%)$

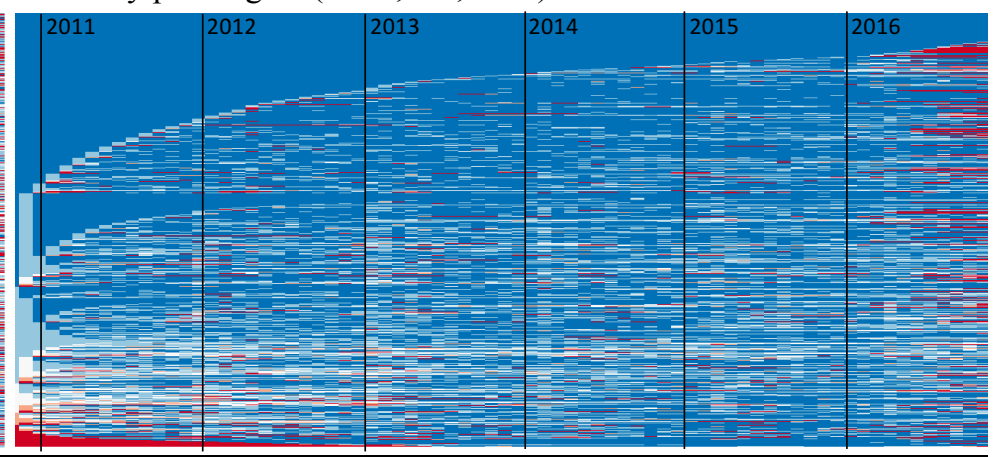

Figure 2. Clusters of temporal boarding profiles and their frequency among 371,220 passengers, who are 66 years or older and have no missing demographic data.

Nevertheless, the event of non-boardings increases from three to 25 per cent in the last year of the study period. Eight per cent of all passholders are assigned to this cluster.

A dramatic trend is shown in cluster 4, which ends with a completely different pattern than it started with. While in 2011, cluster members could be described as regularly seen, a gradual withdrawal began in early 2012 which remained steady since. In August 2016, three in four would not use the bus any more, and continuous usage with more than 26 boardings per episode disappeared entirely. Seven per cent of passholders are part of this cluster.

Cluster 5 consists of similar boarding trends to cluster 4 but the decline occurs later and is sharper in this small cluster of five per cent of passholders. In 2011, nearly 80 per cent use 
the bus several times per week if not daily. In 2016, 80 per cent have abandoned the bus, with the sharpest decline between 2015 and 2016.

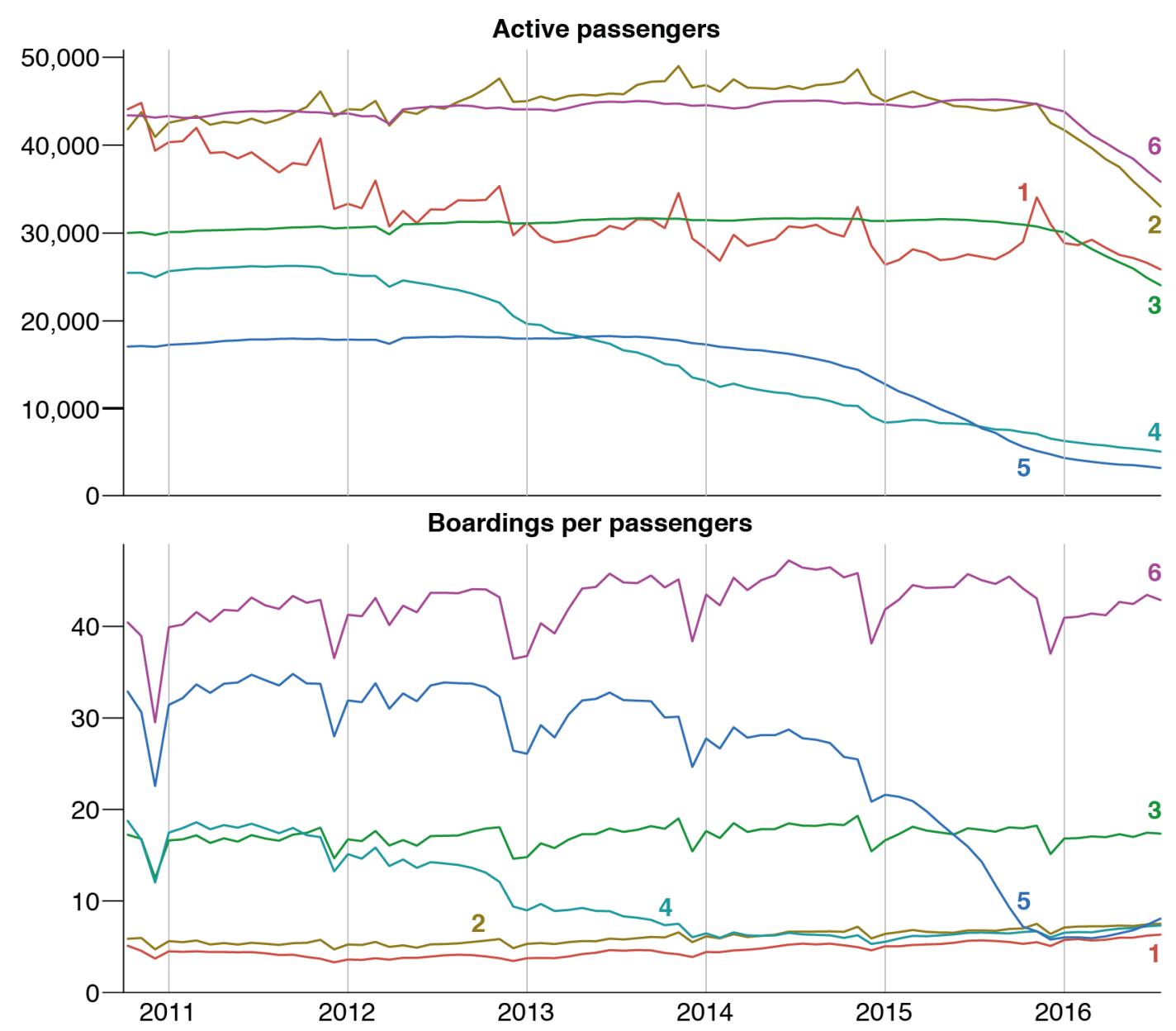

Figure 3. Passengers and boarding rates per cluster.

The final cluster 6 is composed of passengers that use the bus on a daily basis. Episodes with no boardings are rare in this cluster, which comprise 12 per cent of passholders. Yet, even here, an increase in cardholders with no boardings can be observed in 2016.

Accordingly, boardings decrease noticeably given that passengers with high boarding rates switch to no boardings.

Trends in patronage reveal heterogeneity but also some common patterns (Figure 3). The number of active passengers, i.e. those who board at least once in an episode, has remained stable in four clusters $(1,2,3,6)$ and dropped sharply in two clusters $(4,5)$. But there is also a parallel drop in the former group starting at around 2016. In clusters 2, 3 and 6 , patronage dropped by approximately 20 per cent, and in cluster 1 by 30 per cent. At the same time, average boarding rates remained stable, which suggests that passengers of this type withdraw from bus and tram use altogether and do not simply use these modes less frequently. There is, however, a slight increase in boarding rates in clusters of lower patronage $(1,2)$ by about 20 per cent. This implies that passengers in those clusters use the bus more often, but due to infrequence of boardings, the overall decline is not compensated. Clusters 4 and 5 reveal both a consistent decrease in patronage alongside reduced boarding 
rates. This trend suggests that passengers board less frequently before leaving the system altogether.

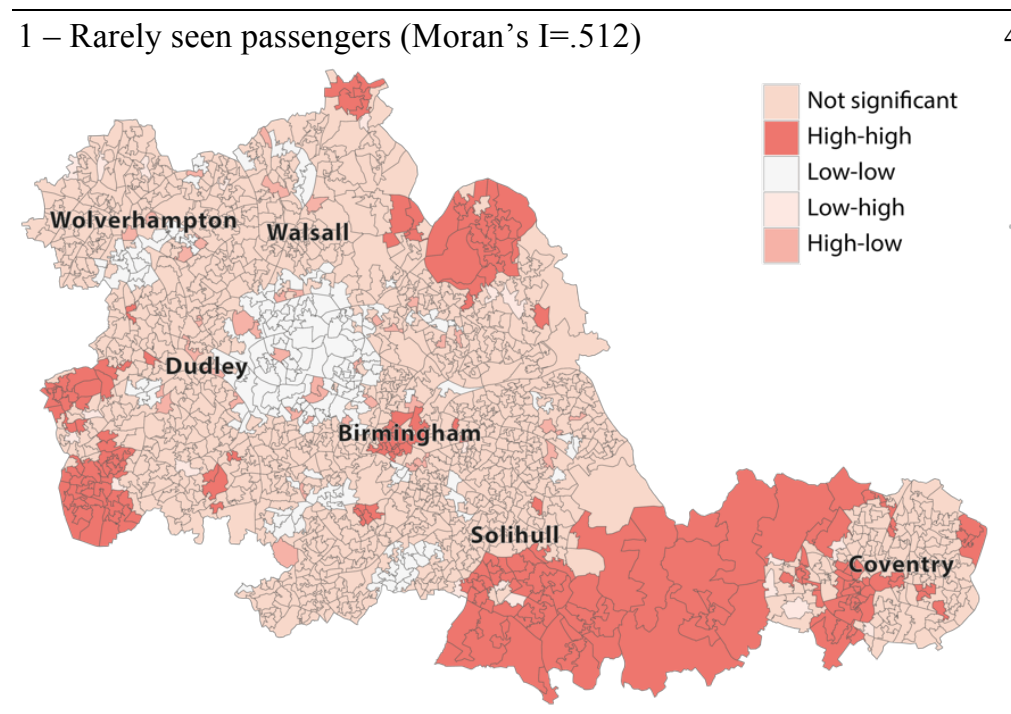

4 - Gradually withdrawing passengers (Moran's I=.148)

2 - Irregular passengers (Moran's I=.364)

5 - Rapidly withdrawing passengers (Moran’s I=.210)
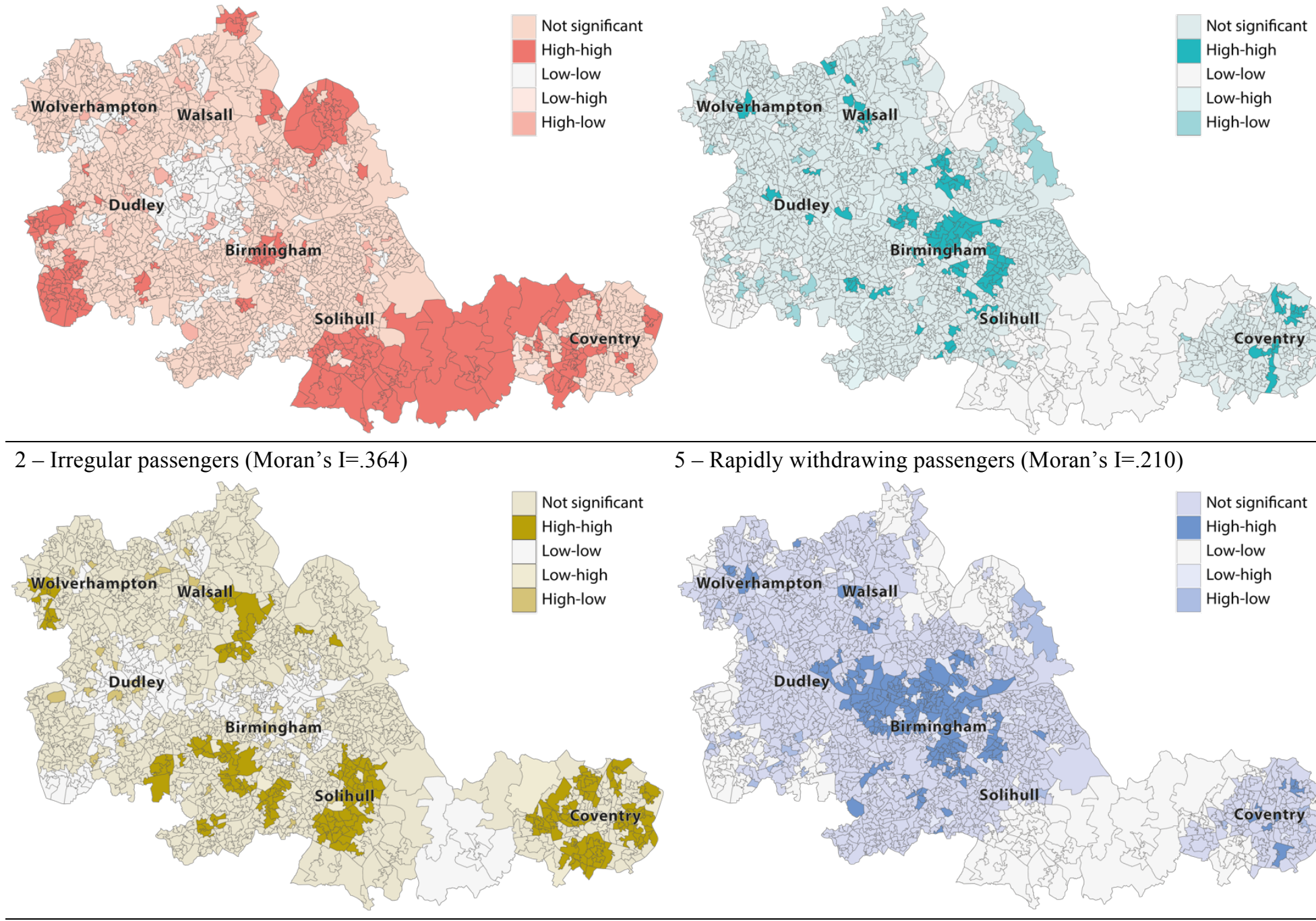

3 - Regularly seen passengers (Moran's I=.269)
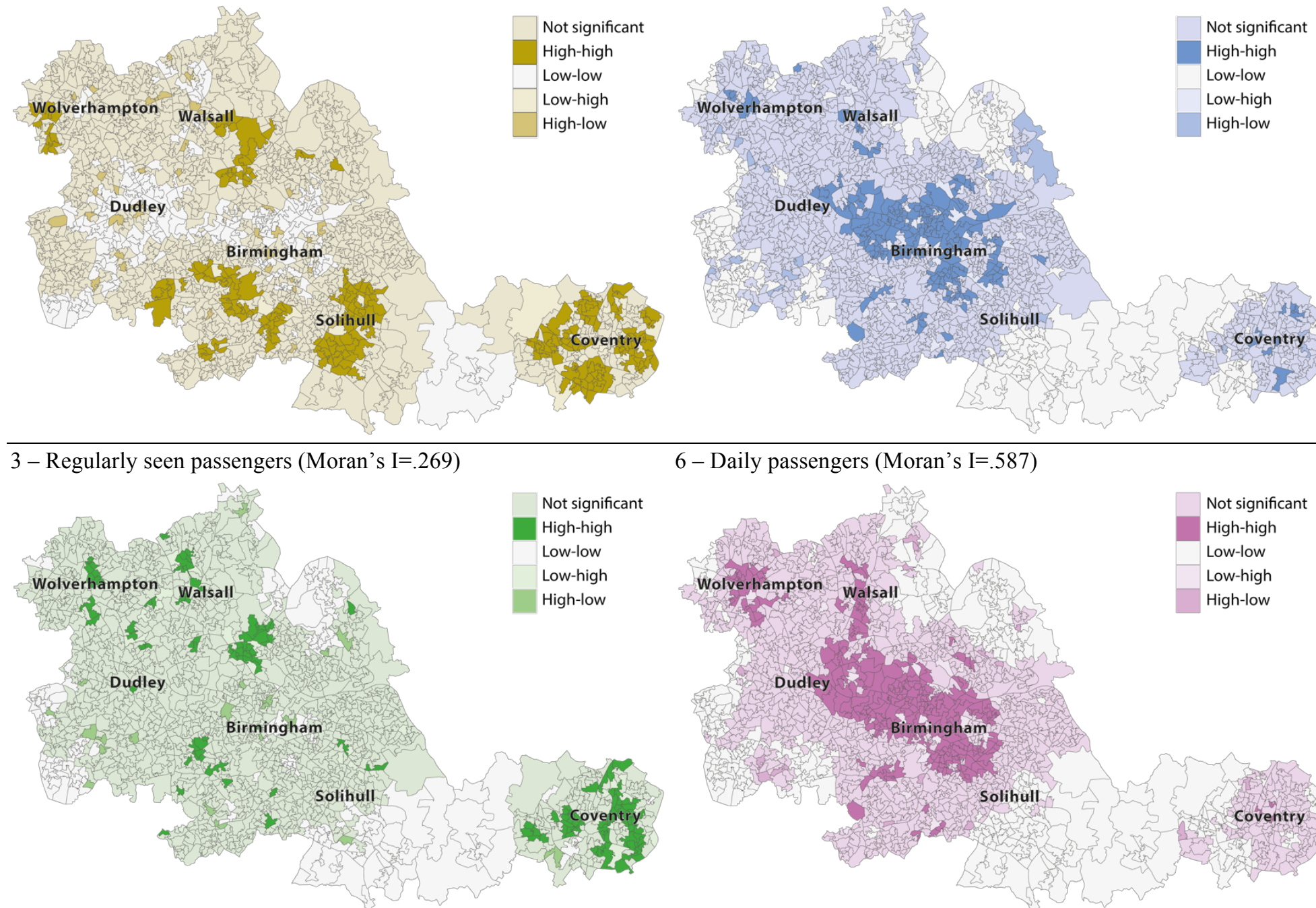

6 - Daily passengers (Moran’s I=.587)

All maps contain Ordnance Survey data. (C) Crown copyright and database right 2018.

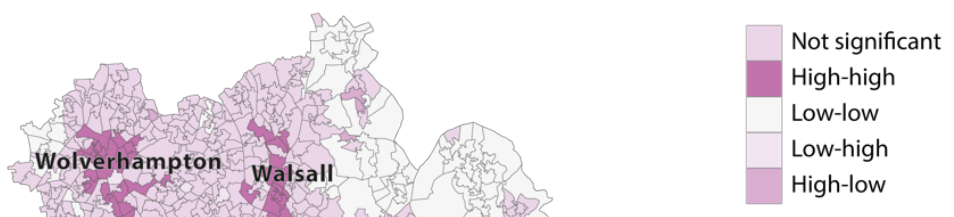

Figure 4. Geographic patterns associated with each cluster. 


\section{Spatial, demographic and neighbourhood context}

For each cluster, a significant spatial pattern can be detected (Figure 4). Rarely seen passengers (cluster 1 ) and daily passengers (cluster 6 ) are the most concentrated groups in the region. The former tend to reside in peripheral parts of the metropolitan region with less population density, specifically between Solihull and Coventry and Walsall. Daily passengers (cluster 6 ) tend to live in central Birmingham and a western corridor stretching towards West Bromwich and in Wolverhampton and Walsall. Parts of this corridor is served by the West Midlands Metro tram.

Irregular passengers (cluster 2) tend to live in suburban parts of the region, such as Solihull and King's Heath, south of central Birmingham, and the suburbs of Coventry. Regularly seen passengers (cluster 3 ) often live in Coventry. The two types of withdrawing passengers (clusters 4 and 5) are located in central Birmingham, particularly in the more deprived and ethnically diverse eastern part of the city. In contrast to cluster 4 , cluster 5 also extends further towards southwest Birmingham and Dudley, encompassing neighbourhoods close to the West Midlands Metro.

The multinomial logit model highlights demographic and neighbourhood characteristics associated with the six temporal boarding profiles (Table 3). The dependent variable is the multinomial cluster membership. We define rarely seen passengers (cluster 1 ) as the reference category.

Table 3. Regression results of the random intercept model

\begin{tabular}{|c|c|c|c|c|c|}
\hline & Cluster 1 & Cluster 3 & Cluster 4 & Cluster 5 & Cluster 6 \\
\hline \multicolumn{6}{|l|}{ passenger } \\
\hline 1 gender male & $.539^{* * *}$ & $-.261^{* * *}$ & $.141^{*}$ & $.271^{* * *}$ & $-.187^{* * *}$ \\
\hline 2 age 76 years or more & $.546^{* * *}$ & $.276^{* * *}$ & $1.393^{* * *}$ & $1.047^{* * *}$ & $.286^{* * *}$ \\
\hline 3 male $* 76$ years or more & $-.405^{* * *}$ & -.086 & $-.351^{* * *}$ & -.250 & .026 \\
\hline \multicolumn{6}{|l|}{ neighbourhood } \\
\hline 4 white population & $.269^{* * *}$ & .015 & $.108^{* *}$ & -.010 & -.031 \\
\hline 5 IMD income in old age & -.055 & $-.100^{*}$ & $-.149^{* * *}$ & $-.228^{* * *}$ & $-.235^{* * *}$ \\
\hline 6 no access to car & $-.148^{* * *}$ & $.118^{* *}$ & $.198^{* * *}$ & $.346^{* * *}$ & $.214^{* * *}$ \\
\hline 7 distance to tram & -.008 & -.048 & -.039 & $-.098^{* *}$ & $-.139^{* * *}$ \\
\hline 8 accessibility to supermarkets & $.078^{* * *}$ & .012 & .030 & $.075^{*}$ & $.069^{* * *}$ \\
\hline $\mathrm{N}$ & & & 53,647 & & \\
\hline DIC & & & 142,954 & & \\
\hline$\Delta \mathrm{DIC}$ & & & $-5,212$ & & \\
\hline \multicolumn{6}{|c|}{$\begin{array}{l}\text { Clusters: } 2 \text { Irregular (reference), } 1 \text { Rarely seen, } 3 \text { Regularly seen, } 4 \text { Gradually withdrawing, } 5 \text { Rapidly withdrawing, } 6 \text { Daily passengers } \\
\text { Significance: p-value } * * * \leq 0.001, * * \leq 0.01, * \leq 0.05 \cdot \text { Cluster sizes: } 29,060(1) ; 5,941(2), 6,251(3), 4,660(4), 1,249(5), 6,486(6) \\
\text { Other accessibility variables (hospitals, GP practices, railway stations, retail centres) correlated highly with accessibility to supermarkets and } \\
\text { trams and were therefore excluded. }\end{array}$} \\
\hline
\end{tabular}

We can observe pronounced patterns with respect to age and gender differences across the six clusters. Rarely seen passengers (cluster 1 ) are often male. Descriptive statistics confirm that men are overrepresented in cluster 1 with $51 \%$ per cent compared to an expected 
sample value of $46 \%$. In clusters with slightly more regular patronage and daily use (clusters 2, 3 and 6 respectively), women are strongly overrepresented with a share of 59 per cent or more. Members of these clusters also tend to be younger. By contrast, the majority in the two withdrawing clusters 4 and 5 are 76 years or older.

Passengers with lower patronage tend to live in less ethnically diverse and more affluent neighbourhoods with lower levels of public transport accessibility and comparatively higher car ownership. This plausible pattern shows some nuances, however, for example, with respect to rarely seen passengers (cluster 1 ), who often live in areas with higher access to supermarkets.

Rarely seen passengers also tend to live in neighbourhoods where the majority of residents describe themselves as 'white' in the Census, which contrasts with most other clusters, who live in more ethnically diverse neighbourhoods. Pronounced differences exist with respect to income context. Gradually and rapidly withdrawing passengers (clusters 4, 5) and daily passengers (cluster 6 ) often live in poorer neighbourhoods compared to rarely and irregularly seen passengers (clusters 1 and 2).

In terms of transport-related context, all but rarely seen passengers (cluster 1 ) live in neighbourhoods with low access to a car. Rapidly withdrawing passengers (cluster 5) and daily passengers (cluster 6 ) tend to live in neighbourhoods with particularly low levels of car ownership but higher access to the tram line and public transport accessibility to supermarkets. We found that accessibility to supermarkets and the tram strongly correlate with accessibility to GP practices, hospitals and railway stations, which we therefore excluded from the final model.

\section{Discussion}

\section{Interpretation: Three potential causal domains}

The clusters of boarding sequences decompose the overall declining patterns into different waves of receding patronage. The first wave is represented by cluster 4 , whose members gradually abandon buses and trams before leaving the system completely. In a second wave, passengers of cluster 5 reduce their patronage more rapidly after 2014 and reach the level of patronage of cluster 4 two years later. A third wave encompasses receding patronage in all remaining cluster, but this trend is marked by fewer boardings per person. Cluster 1 presents a different trend of increased boardings alongside decreasing passenger numbers.

The socio-demographic and geographical patterns associated with these trends suggests that the first two waves are related to old age and thus mortality, although they also occur in a context of stronger social disadvantage. In the third wave, it is only the group of daily passengers (cluster 6 ) who indicate social disadvantage. Since clusters 5 and 6 alone account for 60 per cent of all boardings, their patronage strongly influences the overall, observed trend. As a result, passengers whose socio-spatial context suggests greater 
vulnerability to public transport captivity and social exclusion appear to leave the public transport system more than other passengers.

Table 4. Causal domains, hypotheses and evidence.

\begin{tabular}{|c|c|c|c|}
\hline \multirow{2}{*}{$\begin{array}{l}\text { Hypothesis } \\
\text { Social domain }\end{array}$} & \multicolumn{2}{|c|}{ Support Evidence } & \multirow[t]{2}{*}{ Clusters } \\
\hline & & & \\
\hline $\begin{array}{l}\text { Greater poverty among pensioners leads to } \\
\text { fewer out-of-home activities. }\end{array}$ & pro & $\begin{array}{l}\text { decreasing patronage where income in old age } \\
\text { is lower; recent rise in pensioner poverty in } \\
\text { the UK, especially among single male } \\
\text { pensioners (JRF 2017) }\end{array}$ & 5,6 \\
\hline \multirow[t]{2}{*}{ Online shopping replaces out-of-home trips. } & pro & $\begin{array}{l}\text { gradually less patronage over longer time } \\
\text { period; rise in shopping trends among senior } \\
\text { residents (ONS 2018d) }\end{array}$ & 4,5 \\
\hline & contra & $\begin{array}{l}\text { expected trends observed for older residents } \\
\text { and poorer areas }\end{array}$ & 4,5 \\
\hline \multirow{2}{*}{$\begin{array}{l}\text { Senior residents, particularly women, have } \\
\text { greater access to the car. }\end{array}$} & pro & decreasing patronage by women & 4,5 \\
\hline & contra & $\begin{array}{l}\text { decreasing patronage where car ownership is } \\
\text { lower, slight increase where it is higher }\end{array}$ & $1,4,5$ \\
\hline \multicolumn{4}{|l|}{ Health-related domain } \\
\hline \multirow[t]{2}{*}{ Premature mortality rates are increasing. } & pro & $\begin{array}{l}\text { pronounced decline in patronage by older } \\
\text { groups }\end{array}$ & 4,5 \\
\hline & contra & stable, regional mortality rates (ONS 2018b) & - \\
\hline \multirow[t]{2}{*}{$\begin{array}{l}\text { Earlier onset of mobility-limiting disability } \\
\text { or ill-health among vulnerable groups. }\end{array}$} & pro & $\begin{array}{l}\text { pronounced decline in patronage by older } \\
\text { groups }\end{array}$ & 4,5 \\
\hline & contra & not reflected in higher mortality (ONS 2018b) & - \\
\hline \multicolumn{4}{|l|}{ Structural domain } \\
\hline \multirow[t]{2}{*}{ Cuts in bus routes has reduced accessibility. } & pro & $\begin{array}{l}\text { decreasing patronage where accessibility is } \\
\text { lower }\end{array}$ & 2,3 \\
\hline & contra & $\begin{array}{l}\text { decreasing patronage where accessibility is } \\
\text { high, more boardings where accessibility low }\end{array}$ & 1,6 \\
\hline \multirow[t]{2}{*}{$\begin{array}{l}\text { Extension of the tram attracts demand away } \\
\text { from buses. }\end{array}$} & pro & $\begin{array}{l}\text { fewer boarding in proximity to tram; sharp } \\
\text { increase in tram patronage (DfT 2017) }\end{array}$ & 6 \\
\hline & contra & contra: stable boarding rates per person & 6 \\
\hline \multirow{2}{*}{$\begin{array}{l}\text { Emergence of new ride-sharing and e- } \\
\text { hailing modes attracts demand away from } \\
\text { buses. }\end{array}$} & pro & $\begin{array}{l}\text { decreasing patronage after UBER and GetTaxi } \\
\text { launch in early } 2015\end{array}$ & \\
\hline & contra & decreasing patronage in poorer areas & 5,6 \\
\hline
\end{tabular}

This finding would point towards social causes of declining boarding trends, in a sense that, for example, greater poverty among pensioners may reduce the number of out-of-home or neighbourhood activities. Table 4 lists potential causes triangulated against supporting or contradicting evidence arising from this research and external reports. As for poverty, external evidence shows that pensioner poverty has increased recently in the United Kingdom (JRF 2017); and this rise coincides with the decrease in boardings found in clusters 5 and 6 . Greater poverty may further lead to earlier onset of ill health and mobility-limiting disability, which again would be reflected in receding patronage. Health thus arises as a second potential causal domain, which may explain boarding trends.

Clusters 4 and 5 likely represent those residents who abandon the bus due to very old age and eventually mortality. If we were to attribute receding patronage purely to demographic 
events, we would need to conclude that mortality rates have risen of the last few years in the West Midlands Combined Authority. ONS data, however, suggest that between 2010 and 2016 preventable mortality rates have remained stable, if not reduced slightly (ONS 2018b, 2018c). Yet this trend does not preclude earlier onset of mobility-limiting disability or increasing health inequalities corresponding to passengers in the different clusters.

A third, potential causal domain relates to structural changes in the transport system itself. The spatial analysis of the clusters reveal that reduced boarding rates by daily passengers (cluster 6) often occur in areas with access to the tram. ENCTS passholders resident in the WMCA are entitled to free tram and rail travel. Indeed, tram patronage has increased by 29 per cent between in 2016 (DfT 2017). Just before this period, the tram was extended into the centre of Birmingham from its former terminus outside the centre. It is likely that this extension made bus boardings unnecessary to reach popular inner-city destinations. The smartcard data suggests that tram boardings remain stable through this period. If trams and rail attract patronage away from buses, it suggests that these services cater to the mobility needs of the elderly and should continue to be included in the concessionary scheme.

Another mode affecting bus patronage are emerging ride-sharing and e-hailing services, which were permitted to operate in the region in early 2015. External data would be needed to estimate patronage by senior residents of these services, but the temporal coincidence offers a plausible explanation for the third wave of receding patronage. If this hypothesis can be substantiated, a transport policy goal may be to make public transport more attractive, demand-responsive, transparent and physically accessible. Alternatively, concessionary schemes could at least in parts be extended to such modes. This would be the approach of MaaS (Mobility as a Service), which is currently implemented in the region. Combined voucher schemes or special service packages for elderly citizens may generate synergies and better target the concessionary scheme.

Nevertheless, such solutions should be carefully evaluated as to whether they effectively enable inclusive mobility and are desirable from an environmental perspective alongside inclusion. Passengers in cluster 1 live in less accessible locations and likely depend on cars. Tailored MaaS may be most effective here to bring minimum environmental benefits. For passengers in cluster 2 and 3, such solutions may contribute to inclusion in transport, as they are likely to be less affluent and live in less accessible locations. Yet, passengers in clusters 4 to 6 enjoy higher levels of accessibility and therefore the emphasis should be placed on tailoring existing public transport services better to the needs of these groups. It seems that some degree of geographical adaptation of both ENCTS and MaaS would be appropriate to balance the need for inclusive mobility with environmental concerns

Further changes in the social domain may contribute to receding patronage, but evidence from our analysis is mixed. As older population cohorts become more inclined to adopt technology, trips may be replaced by online shopping, banking, health care and other electronic services. The ONS (2018) found that there has been a sharp rise in online shopping by adults of age 65 in the last decade. This trend may in part explain the first wave of receding patronage, but it seems implausible that those changes would cause the sharp 
and complete withdrawal of the third wave. Increased possession of driving licences among women and access to cars may also constitute a social reason for withdrawal from bus use, but the fact that the decline occurs in neighbourhoods with lower car ownership does not lend strong support to this hypothesis. This hypothesis could be further explored by comparing women's ENTCS patronage across different cohorts over longer time periods. In addition, temporally and spatially granular data on changes in car ownership may generate more certain results with respect to the current role of car use.

\section{Limitations}

Like all 'big' datasets, smartcard data suffer from bias and very limited curation for long-term research purposes. Although the demographic bias in the data are limited and a large part of the population seems to be recorded, the overrepresentation of older age groups reflects the caveat that the database does not record a passenger's death. This limitation affects our ability to untangle social from health-related causes of the decline in boardings. Recognising that establishing causality in 'big' data analysis is challenging, if not impossible, we developed the cause-evidence matrix to gauge the plausibility of potential causes by triangulating our findings with external data.

Deciding an appropriate number of sequence clusters invariably involves subjectivity and pragmatism. Although we applied goodness-of-fit tests of cluster solutions, they each have limitations and need to be supplemented with considerations of interpretability. Six clusters appeared to be statistically defensible and well interpretable among a wider set of alternative solutions.

The boarding sequences count raw boardings and thus treat initial boardings and interchanges equally. Passengers with more interchanges than others thus appear as more regular users in comparison. We estimate that the impact on the results will be limited as the ordinal categories span broad ranges of boarding counts. Nevertheless, counts of full trips would be preferable, which requires further complex linkage of the smartcard data to data with location information, such as GPS-based Automated Vehicle Locations (AVL).

Such linkage would also allow multidimensional representations of long-term boarding sequences. At present, while the data span a time horizon that is unusually long for 'big' data research generally, more journey characteristics could be inferred by imputing boarding and alighting locations. In the West Midlands, AVL data have only become available from mid 2015 and the development and testing of complex algorithms imputing locations from other sources, such as timetables, will be a challenging task for future research.

\section{Concluding remarks}

The analysis of smartcard transactions over a longer time horizon has revealed diverse boarding trends among elderly residents in the West Midlands Combined Authority. The six types of temporal boarding profiles decomposed the overall trend of declining public transport patronage into three waves of receding patronage. A formal statistical analysis 
further contextualised the boarding trends within passenger demographics and neighbourhood characteristics. The clustering of boarding sequences afforded a refined view of heterogeneous temporal boarding profiles, which enabled us to generate hypotheses about these trends in three causal domains. Evidence in support or against these hypotheses may usefully guide further inquiries into the causes of receding public transport patronage in the West Midlands and elsewhere in the United Kingdom.

Our findings suggest that the impact of blanket schemes to promote inclusive mobility may be limited by socially and spatially diverse needs and practices by senior residents. On the one hand, free access to public transport is not necessarily the most effective approach to support independent and autonomous ageing. On the other hand, some potential causes for receding patronage are firmly located outside the transport sector and would require higher levels of government to address systemic barriers to social inclusion in old age.

\section{References}

Anda, C., Erath, A., \& Fourie, P. J. (2017). Transport modelling in the age of big data. International Journal of Urban Sciences, 21, 19-42.

https://doi.org/10.1080/12265934.2017.1281150

Anselin, L. (1995), Local Indicators of Spatial Association-LISA. Geographical Analysis, 27, 93-115. doi:10.1111/j.1538-4632.1995.tb00338.x

Bivand, R., \& Piras, G. (2015). Comparing Implementations of Estimation Methods for Spatial Econometrics. Journal of Statistical Software, 63(18), 1-36. URL http://www.jstatsoft.org/v63/i18/.

Briand, A. S., Côme, E., Trépanier, M., \& Oukhellou, L. (2017). Analyzing year-to-year changes in public transport passenger behaviour using smart card data. Transportation Research Part C: Emerging Technologies, 79, 274-289.

https://doi.org/10.1016/j.trc.2017.03.021

Chu, K. K. A. (2015). Two-year worth of smart card transaction data - Extracting longitudinal observations for the understanding of travel behaviour. In Transportation Research Procedia (Vol. 11). https://doi.org/10.1016/j.trpro.2015.12.031

Chudyk, A. M., Winters, M., Moniruzzaman, M., Ashe, M. C., Gould, J. S., \& McKay, H. (2015). Destinations matter: The association between where older adults live and their travel behavior. Journal of Transport and Health, 2(1), 50-57.

https://doi.org/10.1016/j.jth.2014.09.008

Cohen, J. (1968). "Weighted kappa: Nominal scale agreement with provision for scaled disagreement or partial credit". Psychological Bulletin. 70 (4): 213-220.

https://doi.org/10.1037/h0026256 
Cui, J., Loo, B. P. Y., \& Lin, D. (2017). Travel behaviour and mobility needs of older adults in an ageing and car-dependent society. International Journal of Urban Sciences, 21(2), 109128. https://doi.org/10.1080/12265934.2016.1262785

DfT 2017. Light Rail and Tram Statistics: England 2016/17. (Department for Transport). Retrieved from:

https://assets.publishing.service.gov.uk/government/uploads/system/uploads/attachment da ta/file/623366/light-rail-tram-ending-march-2017.pdf.

Everitt, B. S. et al. (2011). Cluster Analysis. New York: John Wiley \& Sons, Ltd.

Farber, S., Morang, M. Z., \& Widener, M. J. (2014). Temporal variability in transit-based accessibility to supermarkets. Applied Geography, 53, 149-159.

https://doi.org/10.1016/j.apgeog.2014.06.012

Gabadinho, A., Ritschard, G., Müller, N. S., \& Studer, M. (2011). Analyzing and Visualizing State Sequences in R with TraMineR. Journal of Statistical Software, 40(4), 1-37. DOI http://dx.doi.org/10.18637/jss.v040.i04.

Gauthier JA., Bühlmann F., Blanchard P. (2014) Introduction: Sequence Analysis in 2014. In: Blanchard P., Bühlmann F., Gauthier JA. (eds) Advances in Sequence Analysis: Theory, Method, Applications. Life Course Research and Social Policies, vol 2. Springer, Cham

Geolytix (2018). GeoLytix Open Supermarkets Version 5. Retrieved from https://geolytix.co.uk/?retail points.

Goulet Langlois, G., Koutsopoulos, H. N., \& Zhao, J. (2016). Inferring patterns in the multiweek activity sequences of public transport users. Transportation Research Part C:

Emerging Technologies, 64, 1-16. https://doi.org/10.1016/j.trc.2015.12.012

Green, J., Jones, A., \& Roberts, H. (2014). More than A to B: The role of free bus travel for the mobility and wellbeing of older citizens in London. Ageing and Society, 34(3), 472-494. doi:10.1017/S0144686X12001110

Hadfield, J. D. (2010). MCMC methods for multi-response generalized linear mixed models: the MCMCglmm R package. Journal of Statistical Software, 33(2), 1-22.

https://doi.org/10.1002/ana.22635

Greener Journeys \& KPMG (2014). Bus 2020. The Case for the Bus. Retrieved from https://greenerjourneys.com/wp-content/uploads/2015/02/Bus-2020.pdf.

Hamming, R. W. (1950). Error-detecting and error-correcting codes. Bell System Technical Journal, 26(2), 147-160.

Haustein, S. (2012). Mobility behavior of the elderly: An attitude-based segmentation approach for a heterogeneous target group. Transportation, 39(6), 1079-1103.

https://doi.org/10.1007/s11116-011-9380-7 
Huang, J., Levinson, D., Zhou, J., Wang, Z., \& Wang, J. (2018). Tracking job and housing dynamics with smartcard data. Proceedings of the National Academy of Sciences, 115(50), 12710-12715. https://doi.org/10.1073/pnas.1815928115

Joh, C.-H., \& Timmermans, H. (2011). Applying Sequence Alignment Methods to Large Activity-Travel Data Sets. Transportation Research Record: Journal of the Transportation Research Board, 2231, 10-17. https://doi.org/10.3141/2231-02

JRF (2017). UK Poverty 2017. A comprehensive analysis of poverty trends and figures. (Joseph Rowntree Foundation). Retrieved from https://www.jrf.org.uk/report/uk-poverty2017.

Langfelder, P, and Horvath, S. (2012). Fast R Functions for Robust Correlations and Hierarchical Clustering. Journal of Statistical Software, 46(11), 1-17. URL http://www.jstatsoft.org/v46/i11/.

Levenshtein, V. (1966). Binary codes capable of correcting deletions, insertions and reverslas. Cybernetic Control Theory, 10(8), 707-710.

Lucas, K. (2012). Transport and social exclusion: Where are we now? Transport Policy 20, 105-113. https://doi.org/10.1016/j.tranpol.2012.01.013.

Luiu, C., Tight, M., \& Burrow, M. (2017). The unmet travel needs of the older population: a review of the literature. Transport Reviews, 37(4), 488-506.

https://doi.org/10.1080/01441647.2016.1252447

Mackett, R. (2017). Older People's Travel and its Relationship to their Health and Wellbeing. In: Musselwhite, C. (ed.) Transport, Travel and Later Life (Transport and Sustainability, Volume 10). Emerald Publishing Limited, pp.15 - 36.

Mackett, R. (2014). Has the policy of concessionary bus travel for older people in britain been successful? Case Studies on Transport Policy, 2(2), 81-88.

https://doi.org/10.1016/j.cstp.2014.05.001

Mackett, R. (2013). Impact of Concessionary Bus Travel on the Well-Being of Older and Disabled People, Transportation Research Record (2352), 114-119.

https://doi.org/10.3141/2352-13

MHCLG 2015. English Indices of Deprivation 2015 - LSOA Level. (Ministry of Housing, Communities \& Local Government). Retrieved from http://opendatacommunities.org/data/societal-wellbeing/imd/indices.

Musselwhite, C., Holland, C., \& Walker, I. (2015). The role of transport and mobility in the health of older people. Journal of Transport and Health, 2(1), 1-4.

https://doi.org/10.1016/j.jth.2015.02.001

NHS Digital (2018). Organisation Data Service. Retrieved from https://digital.nhs.uk/services/organisation-data-service. 
ONS 2019. Lower layer Super Output Area population estimates. (Office for National Statistics). Retrieved from

https://www.ons.gov.uk/peoplepopulationandcommunity/populationandmigration/populatione stimates/datasets/lowersuperoutputareamidyearpopulationestimates.

ONS 2018a. 2011 Census Data On Nomis. (Office for National Statistics). Retrieved from https://www.nomisweb.co.uk/census/2011.

ONS 2018b. Avoidable Mortality in England and Wales, 2013. (Office for National Statistics). Retrieved from

https://www.ons.gov.uk/peoplepopulationandcommunity/healthandsocialcare/causesofdeath/ datasets/avoidablemortalityinenglandandwalesreferencetable2.

ONS 2018c. Avoidable, amenable, and preventable age-standardised mortality rates, by sex, for England and the West Midlands, 2014 to 2016. (Office for National Statistics).

Retrieved from

https://www.ons.gov.uk/peoplepopulationandcommunity/healthandsocialcare/causesofdeath/ adhocs/008714avoidableamenableandpreventableagestandardisedmortalityratesbysexforen glandandthewestmidlands2014to2016.

ONS 2018d. Internet access - households and individuals, Great Britain: 2018. (Office for National Statistics). Retrieved from

https://www.ons.gov.uk/peoplepopulationandcommunity/householdcharacteristics/homeinter netandsocialmediausage/bulletins/internetaccesshouseholdsandindividuals/2018\#olderadults-show-largest-increase-in-online-shopping-over-the-past-decade.

ONS 2017a. National Population Projections: 2016-based statistical bulletin. (Office for National Statistics). Retrieved from

https://www.ons.gov.uk/peoplepopulationandcommunity/populationandmigration/populationp rojections/bulletins/nationalpopulationprojections/2016basedstatisticalbulletin.

ONS 2017b. Population Weighted Centroids Guidance. (Office for National Statistics).

Retrieved from https://data.gov.uk/dataset/2c5695f2-39d0-457f-a03c-

1f4d3617bb48/population-weighted-centroids-guidance.

OpenTripPlanner 2018. Retrieved from http://www.opentripplanner.org/.

Ordinance Survey 2018. OS Open Roads. Retrieved from

https://www.ordnancesurvey.co.uk/business-and-government/products/os-open-roads.html.

Pavlis M., Dolega L., \& Singleton A. (2017). A Modified DBSCAN Clustering Method to

Estimate Retail Center Extent. Geographical Analysis, 50(2), 141-161.

https://doi.org/10.1111/gean.12138

Pelletier, M., Trépanier, M., \& Morency, C. (2011). Smart card data use in public transit : A literature review. Transportation Research Part C, 19(4), 557-568.

https://doi.org/10.1016/j.trc.2010.12.003 
Schwanen, T., Lucas, K., Akyelken, N., Solsona, D.C., Carrasco, J.A. and Neutens, T. (2015). Rethinking the links between social exclusion and transport disadvantage through the lens of social capital. Transportation Research Part A; Policy and Planning.

https://doi.org/10.1016/j.tra.2015.02.012

Schwanen, T., Banister, D., \& Bowling, A. (2012). Independence and mobility in later life. Geoforum, 43(6), 1313-1322. https://doi.org/10.1016/j.geoforum.2012.04.001

Schwanen, T., \& Páez, A. (2010). The mobility of older people - an introduction. Journal of Transport Geography, 18(5), 591-595. https://doi.org/10.1016/j.jtrangeo.2010.06.001

Siren, A., \& Haustein, S. (2016). How do baby boomers' mobility patterns change with retirement? Ageing and Society, 36(5), 988-1007.

https://doi.org/10.1017/S0144686X15000100

Siren, A., \& Haustein, S. (2013). Baby boomers' mobility patterns and preferences: What are the implications for future transport? Transport Policy, 29, 136-144.

https://doi.org/10.1016/j.tranpol.2013.05.001

Spurr, T., Chu, A., Chapleau, R., \& Piché, D. (2015). A smart card transaction "travel diary" to assess the accuracy of the Montréal household travel survey. In Transportation Research Procedia (Vol. 11). https://doi.org/10.1016/j.trpro.2015.12.030

Studer, Matthias (2013). WeightedCluster Library Manual: A practical guide to creating typologies of trajectories in the social sciences with R. LIVES Working Papers, 24. DOI: 10.12682/lives.2296-1658.2013.24.

Studer, M. \& Ritschard, G. (2016). What matters in differences between life trajectories: A comparative review of sequence dissimilarity measures, Journal of the Royal Statistical Society, Series A, 179(2), 481-511. DOI http://dx.doi.org/10.1111/rssa.12125

Schwanen, T., Banister, D., \& Bowling, A. (2012). Independence and mobility in later life. Geoforum, 43(6), 1313-1322. https://doi.org/10.1016/j.geoforum.2012.04.001

Sheller, M. \& Urry, J. (2006). The New Mobilities Paradigm. Environment and Planning A, 38(2), 207-226.

Urry, J. (2014). Social networks, mobile lives and social inequalities. Journal of Transport Geography, 21, 24-30.

Tao, S., Rohde, D., \& Corcoran, J. (2014). Examining the spatial-temporal dynamics of bus passenger travel behaviour using smart card data and the flow-comap. Journal of Transport Geography, 41. https://doi.org/10.1016/j.jtrangeo.2014.08.006

Tenkanen, H., Saarsalmi, P., Järv, O., Salonen, M., \& Toivonen, T. (2016). Health research needs more comprehensive accessibility measures: integrating time and transport modes from open data. International Journal of Health Geographics, 15(1), 23.

https://doi.org/10.1186/s12942-016-0052-x 
TfWM (2018). Transport Plan 2017/18. (Transport for West Midlands). Retrieved from https://www.tfwm.org.uk/media/2435/transport-plan-2017-2018.pdf.

van den Berg, P., Arentze, T., \& Timmermans, H. (2011). Estimating social travel demand of senior citizens in the Netherlands. Journal of Transport Geography, 19(2), 323-331. https://doi.org/10.1016/j.jtrangeo.2010.03.018

Webb, E., Laverty, A., Mindell, J., Millett, C. (2016). Free bus travel and physical activity, gait speed, and adiposity in the english longitudinal study of ageing. American Journal of Public Health, 106 (1), pp. 136-142. DOI: 10.2105/AJPH.2015.302907

WMOD (2018). West Midlands Bus Patronage. (West Midlands Open Datastore). Retrieved from http://opendatawestmids.org.uk/dataset/west-midlands-bus-

patronage/resource/a956d123-3441-4a60-aaf3-33365fbd10d8.

Yue, Y., Lan, T., Yeh, A. G. O., \& Li, Q. Q. (2014). Zooming into individuals to understand the collective: A review of trajectory-based travel behaviour studies. Travel Behaviour and Society, 1(2), 69-78. https://doi.org/10.1016/j.tbs.2013.12.002

Ziegler, F., \& Schwanen, T. (2011). "I like to go out to be energised by different people": An exploratory analysis of mobility and wellbeing in later life. Ageing and Society, 31(5), 758781. https://doi.org/10.1017/S0144686X10000498 